\title{
Pharmaceutical industry exposure in our hospitals: the final frontier
}

"Health services he relationship between the medical profession and the pharmaceutical industry has changed considerably over the last two decades. While in shifting cultural

and financial

reliance away

from

\section{pharmaceutical}

company

sponsorship"

Jessica Dean

BMedSci(Hons)

Erwin Loh MBBS, PhD, FRACMA',

Justin J Coleman MBBS, FRACGP, MPH ${ }^{3.4}$

1 Monash University Melbourne, VIC

2 Monash Health

Melbourne, VIC

3 Inala Indigenous Health

Service, Brisbane, QLD.

4 Griffith University

Southport, QLD.

erwin.loh@monash.edu

doi: 10.5694/mjal5.00734

Online first 11/01/16

Podcast available at

www.mja.com.au/

multimedia/podcasts

the days of expenses-paid overseas conferences and golf trips may be over, pharmaceutical company presence is still felt not only in private practice but also in our hospitals.

Some of these interactions benefit patients; in particular, industry-sponsored clinical trials and research studies in hospitals. Besides generating new evidence and drugs, patients who participate in clinical trials in hospitals appear to have better outcomes and lower mortality. ${ }^{1}$ However, there is a risk that industry sponsorship may unduly influence clinician researchers or the hospital itself. To reduce (but not eliminate) this risk, hospitals must comply with mandatory national research governance frameworks through the implementation of local policies and procedures, and researcher codes of conduct, overseen by research ethics committees. ${ }^{2}$

On the other hand, pharmaceutical company-sponsored medical education for doctors and students risks the presentation of biased evidence and subsequent poorer treatment choices for patients. All industry influence in hospitals should be transparently acknowledged and carefully examined in order to minimise potential harms.

Universities and hospitals have a mixed record when it comes to protecting doctors and medical students from making biased decisions by implementing policies to restrict exposure. Across Australia, health services struggle to take the final step to eradicate pharmaceutical company presence. This hesitation may be due to subtle underlying cultural and financial dependence on pharmaceutical company sponsorship, as well as a commonly held belief that small exposures are fairly harmless.

This contrasts with the community sector, where the No Advertising Please campaign launched in 2014 (http:// www.noadvertisingplease.org) encouraged doctors to pledge to avoid ever seeing pharmaceutical company representatives, recognising that prescribing decisions are influenced even by these small exposures to marketing.

One of the biggest obstacles to complete eradication of undue influence from advertising is that the medical community continues to hold positive attitudes towards market-oriented activities of the pharmaceutical and medical device industries. ${ }^{3,4}$ This is often correlated with the belief that the information from pharmaceutical company representatives is trustworthy, and that these interactions are therefore beneficial to patient care. ${ }^{5}$ Some argue that this commercial promotion is far more effective in conveying essential information to clinicians than publicly funded drug information and, therefore, that we

\section{Summary}

- Despite recent changes in attitudes, most hospitals continue to experience pharmaceutical industry presence.

- Pharmaceutical industry presence may be necessary and beneficial in the context of sponsorship of clinical trials with appropriate governance.

- Doctors continue to hold positive attitudes towards market-oriented activities of the pharmaceutical and medical device industries.

- Despite evidence to the contrary, doctors believe they are able to effectively manage pharmaceutical sales representative interactions such that their own prescribing is not adversely impacted.

- Doctors also share a belief that small gifts and benefits are harmless.

- There may be significant financial burden associated with divestment of such sponsorship by hospitals.

- Change requires education and effective policies to manage pharmaceutical industry relationships and conflicts of interest.

- We discuss case studies involving students and public hospital doctors to show that divestment is possible without significant financial detriment.

- Health services need to be proactive in transitioning financial and cultural reliance on pharmaceutical industry sponsorship to other potentially less harmful sources.

should be prepared to tolerate influence on prescribing behaviour.

In a 2010 systematic review, ${ }^{7}$ Spurling and colleagues effectively excluded the existence of any reliable evidence that information sourced from pharmaceutical company representatives improves the prescribing habits of doctors. In the robust debate following the No Advertising Please campaign, the pharmaceutical industry was unable to point to any such evidence.

Despite acknowledgement of study findings to the contrary, doctors commonly state that they are able to effectively manage pharmaceutical company representative interactions such that their own prescribing is not adversely impacted. ${ }^{5}$ In one study, whereas $51 \%$ of surveyed doctors agreed that pharmaceutical company representatives had a large influence on other doctors' prescribing habits, only $1 \%$ believed that this influence applied to themselves.

Another reason for the loss of momentum is that doctors share a belief that a sponsored lunch at a morbidity and mortality meeting, for example, is harmless; that a small exposure, be it a gift or sponsored lunch, is unlikely to 
have a significant impact on prescribing practices. ${ }^{7,9}$ Yet the pharmaceutical industry, which owes it to shareholders to be at the forefront of marketing psychology, continues to spend billions of dollars on this small-scale sponsorship. In a trial involving 352 medical students, exposure to a logo on a notepad or clipboard resulted in more favourable implicit attitudes about that brand-name drug compared with the control group..$^{10}$

Exposure to pharmaceutical products and branding is likely to affect an individual's objectivity towards the brand, and his or her prescribing behaviour in relation to associated products. A 2010 systematic review showed that doctors' exposure to pharmaceutical promotional material was associated with, on average, higher prescribing frequency, higher costs and lower prescribing quality. ${ }^{7}$ In 2011, a systematic review found that medical students' exposure to pharmaceutical company marketing increased positive attitudes towards that exposure. ${ }^{11}$

\section{Change requires a two-pronged approach}

First, ongoing education continues to be necessary to inculcate change in the profession regarding pharmaceutical industry interactions. ${ }^{5}$ Education, particularly of trainees, should be part of this cultural transition, ${ }^{3}$ as there is some evidence that education is protective; in places of strict pharmaceutical regulation, individuals are less influenced when exposure does occur. ${ }^{10}$ Education aims to eradicate the belief that an individual is exempt from influence, and to improve reception to organisational change.

Second, specific policies and strategies must be consistently implemented. ${ }^{5}$ These should address pharmaceutical company relationships specifically, as well as conflicts of interest more generally. ${ }^{11} \mathrm{~A}$ united approach would be ideal, with reinforcement and support from colleges and registration boards. All members of health care staff require education and support regarding conflict of interest policies and procedures. These strategies are already being achieved at a medical school level ${ }^{4,11}$ and need to be effectively implemented at a health service level.

The systems that many public hospitals currently use to promote appropriate prescribing behaviour should be reinforced. These include formulary systems, electronic medical management systems, drug and therapeutic committees, prescribing guidelines, clinical pharmacist input, antimicrobial stewardship programs, and therapeutic equivalence programs. These systems should remain strictly independent of any pharmaceutical industry input, and merely recording conflicts of interest at the start of meetings is an inadequate solution. Pharmaceutical company-sponsored clinical trials are an important component of medical research that occurs in hospitals, and such systems reduce undue influence.

The financial burden associated with this form of divestment is acknowledged, and therefore a gradual transition may be ideal. Various organisations within the medical

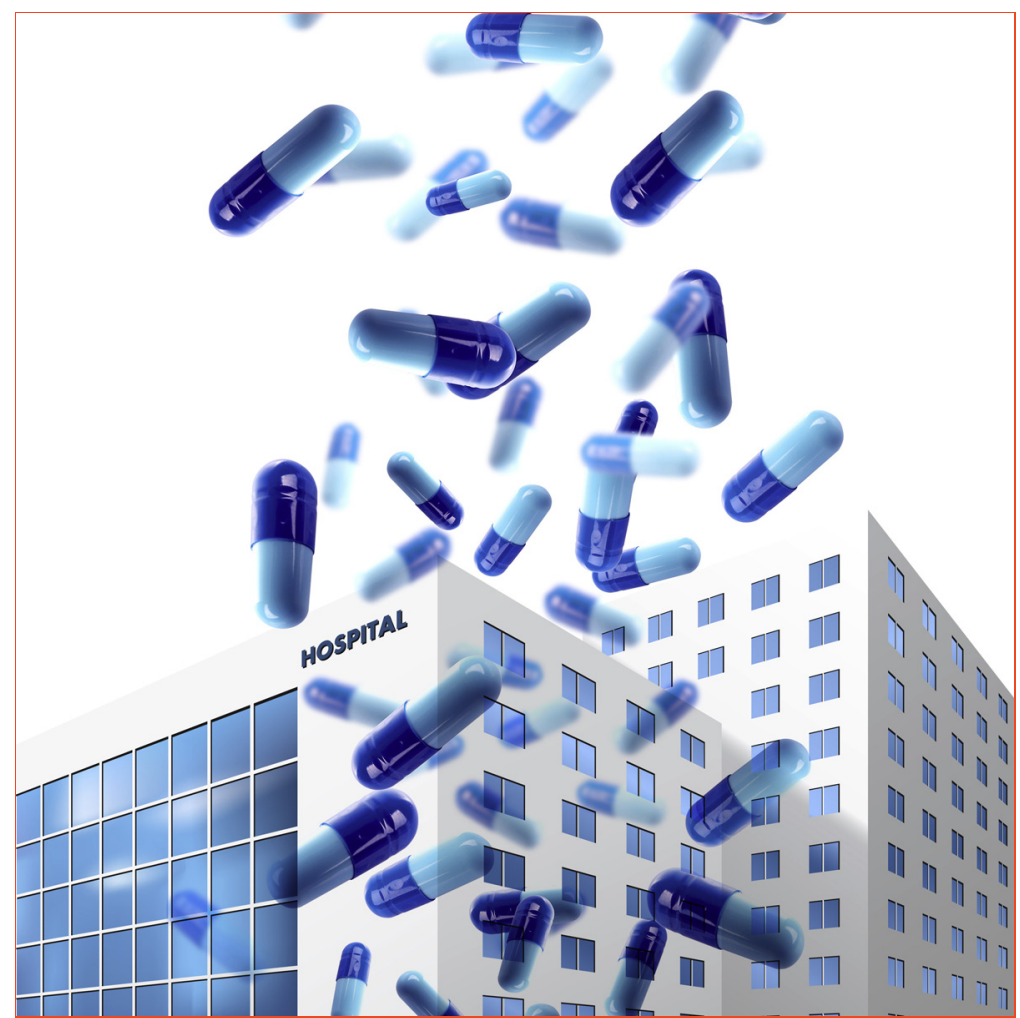

community have managed to effectively transition away from reliance on pharmaceutical company money, sometimes instead accepting alternative sponsorship, such as from medical defence or medical finance organisations. $^{12}$

\section{Case study 1: medical students}

The Australian Medical Students' Association (AMSA) was the first Australian medical organisation to completely remove reliance on pharmaceutical company sponsorship. This was later mirrored in America, where the American Medical Students' Association did the same, as part of a rigorous conflicts of interest reform. ${ }^{13}$

From 1994 to 2004, the issue of pharmaceutical company sponsorship at AMSA events was hotly and repeatedly contested. At the July 2005 AMSA Council, following an extensive survey of medical students' attitudes, representatives from each of the Australian medical schools passed the policy. In 2007, a working party examined the research on the influence of pharmaceutical exposure on medical students and eventually drafted the AMSA guidelines governing these interactions. ${ }^{14}$ Over the next few years, AMSA gradually moved sponsorship opportunities nationally to medical indemnity and financial organisations. As an organisation with an annual turnover of \$3.2 million and heavily dependent on sponsorship, this was no small feat. Current AMSA sponsorship guidelines are so rigorous that they preclude companies with a subsidiary that sells pharmaceutical products. ${ }^{12}$ This case study shows that reliance on pharmaceutical 
company sponsorship can be removed successfully at an undergraduate level.

\section{Case study 2: public hospital doctors}

Monash Health is Victoria's largest public health service, covering five major hospitals, and the Monash Doctors Workforce and Education units at Monash Health have successfully transitioned financial reliance away from pharmaceutical company sponsorship. While pharmaceutical industry presence in the health service still exists through the sponsorship of clinical trials, these two centralised medical workforce and education departments are now successfully free from pharmaceutical company influence, with any resources or sponsorship required for training events now internally funded by the organisation. In addition, the annual Monash Doctors Careers Expo held at Monash Health is now exclusively sponsored by medical finance and medical insurance organisations, as are the Monash Doctors Education junior doctor tutorials and interprofessional orientations. This case study shows that health services can successfully move away from a dependence on pharmaceutical company sponsorship for their workforce and education events.

Health services must be proactive in shifting cultural and financial reliance away from pharmaceutical company sponsorship. This transition is possible without significant financial detriment and is important for independent prescribing decisions. No justifications for the presence of pharmaceutical industry exposure in our health services remain, aside from sponsored clinical trials. Complete eradication rather than minimisation is an essential goal for appropriate patient care.

Competing interests: Erwin Loh is the Chief Medical Officer of Monash Health and a member of the Consultative Council for Clinical Trials Research in Victoria.

Provenance: Not commissioned; externally peer reviewed. n

(c) 2016 AMPCo Pty Ltd. Produced with Elsevier B.V. All rights reserved.

References are available online at www.mia.com.au. 
1 Majumdar S, Roe MT, Peterson ED, et al. Better outcomes for patients treated at hospitals that participate in clinical trials. Arch Intern Med 2008; 168: 657-662.

2 National Health and Medical Research Council. National Statement on Ethical Conduct in Human Research. (2007) (Updated May 2015). https://www.nhmrc.gov.au/book/ national-statement-ethical-conduct-human-research (accessed Nov 2015).

3 Korenstein D, Keyhani S, Ross JS. Physician attitudes toward industry: a view across the specialties. Arch Surg 2010; 145: 570-577.

4 Chimonas S, Brennan TA, Rothman DJ. Physicians and drug representatives: exploring the dynamics of the relationship. J Gen Intern Med 2007; 22: 184-190.

5 Fischer M, Keough ME, Baril JL, et al. Prescribers and pharmaceutical representatives: why are we still meeting? J Gen Intern Med 2009; 24: 795-801.

6 Henry D. Doctors and drug companies: still cozy after all these years. PLoS Med 2010; 7: el000359.

7 Spurling GK, Mansfield PR, Montgomery BD, et al. Information from pharmaceutical companies and the quality, quantity, and cost of physicians' prescribing: a systematic review. PLOS Med 2010; 7: el000352.
8 Steinman MA, Shlipak MG, McPhee SJ. Of principles and pens: attitudes and practices of medicine house staff toward pharmaceutical industry promotions. Am J Med 2001; 110: 551-557.

9 Morgan MA, Dana J, Loewenstein G, et al. Interactions of doctors with the pharmaceutical industry. J Med Ethics 2006; 32: 559-563.

10 Grande D, Frosch DL, Perkins AW, Kahn BE. Effect of exposure to small pharmaceutical promotional items on treatment preferences. Arch Intern Med 2009; 169: 887-893.

1 Austad KE, Avorn J, Kesselheim AS. Medical students' exposure to and attitudes about the pharmaceutical industry: a systematic review. PLoS Med 2011; 8: e1001037.

12 Australian Medical Students' Association. Policy document: pharmaceutical sponsorships policy. Canberra: AMSA, 2014. https://www.amsa.org.au/wp-content/uploads/2014/10/20141 0_Pharmaceutical_Sponsorship_Policy.pdf (accessed Nov 2015).

13 Moghimi Y. The "PharmFree" campaign: educating medical students about industry influence. PLoS Med 2006; 3: e30.

14 Australian Medical Students' Association. Guidelines for the interaction between pharmaceutical companies and Australian medical students. Canberra: AMSA, 2008. 